\title{
¿DEL «RENACIMIENTO» LITERARIO AL NACIONALISMO POLITICO? UNA COMPARACIÓN ENTRE LOS TERRITORIOS DE LENGUA CATALANA Y LOS DE LENGUA VASCA $(1850-1900)^{1}$
}

\author{
From literary "revival" to political nationalism? \\ A comparison between the Catalan \\ and Basque-speaking territories (1850-1900)
}

XABIER ZABALTZA

Universidad del País Vasco/Euskal Herriko Unibertsitatea

xabier.zabaltza@ehu.eus

Resumen

Con una perspectiva comparada, este artículo estudia el origen de los conceptos Renaixença y Pizkunde y mantiene dos tesis complementarias. En primer lugar, los «renacimientos» de las lenguas catalana y vasca se produjeron dentro del proceso de construcción de España (y Francia) como nación. El regionalismo (y sus variantes) es una de las posibles vías de nacionalización y catalanes y vascos no eran los únicos que,

\footnotetext{
Este trabajo forma parte del proyecto de investigación MINECOG14/P11, financiado por el Ministerio de Economía y Competitividad. Agradezco a los profesores Joseba Agirreazkuenaga, Fernando Molina, Xosé-Manoel Núñez Seixas, August Rafanell y Rafael Roca sus aportaciones para mejorar el manuscrito.
} 
en la segunda mitad del Xıx, concebían a España como una nación plurilingüe. Y, en segundo lugar, el paso de las reivindicaciones culturales a las políticas es la excepción, no la regla. Entre los ejemplos analizados, solo en Cataluńa puede vislumbrarse, con varias matizaciones, cierta continuidad entre "renacimiento" y nacionalismo. En los otros territorios de lengua catalana la identidad local sigue manifestándose en términos provinciales o regionales, no nacionales. Por su parte, en los países de lengua vasca, el nacionalismo político surgió de modo autónomo del «renacimiento» literario en vascuence. Además de la industrialización y de la actitud de las élites, la situación sociolingüística de partida, la persistencia o no de las instituciones del Antiguo Régimen y el influjo de movimientos semejantes en otros países son factores que han determinado la historia de estos territorios y, por lo tanto, deberían ser tenidos en cuenta a la hora de establecer modelos historiográficos.

\section{Palabras clave}

Renacimiento literario; lengua catalana; lengua vasca; regionalismo; nacionalismo.

\section{Abstract}

With a comparative perspective, this paper studies the origins of the concepts Renaixença and Pizkunde and holds two complementary theses. First, the "revivals" of the Catalan and Basque languages took place within the Spanish (and French) nation-building process. Regionalism (and its variants) is one of the possible ways of nationalization and, in the second half of the 19th century, Catalans and Basques were not the only ones who conceived of Spain as a multilingual nation. And second, the transition from cultural to political claims is the exception rather than the rule. Amongst the studied examples, only in Catalonia (and with many nuances) can some continuity be detected between "revival" and nationalism. In the other Catalan-speaking areas, local identity continues to manifest itself in provincial or regional terms, not in national terms. On the other hand, in the Basque-speaking countries, political nationalism emerged autonomously from the literary "revival" in the Basque language. In addition to industrialization and the attitude of the elites, the sociolinguistic situation in origin, the persistence (or not) of the institutions of the Ancien Régime, and the influences of similar movements in other countries are factors that have determined the history of these territories and, therefore, they should be taken into account when establishing historiographical models.

\section{Keywords}

Literary revival; Catalan language; Basque language; regionalism; nationalism. 
I. RENAIXENCCA Y PIZKUNDE. II. JOCS FLORALS Y KOPLARIEN GUDUAK. III. CULTURALISMO, PROVINCIALISMO Y REGIONALISMO. IV. CONCLUSIONES. BIBLIOGRAFÍA.

\section{RENAIXENCA Y PIZKUNDE}

El concepto de «renacimiento cultural» o «literario» es un paradigma que se suele utilizar para describir los procesos de reelaboración de los fundamentos de las identidades colectivas, mayormente subestatales, en el siglo XIX ${ }^{2}$. En la tipología clásica de Miroslav Hroch ${ }^{3}$, el «período de interés académico», que coincide con lo que aquí se denomina «renacimiento", se convierte en la fase A de la evolución de los «movimientos nacionales» de los «grupos étnicos no dominantes». Idealmente, a la fase A seguiría la fase B, de agitación patriótica, y a esta la fase C, o movimiento de masas. Hroch estableció su esquema basándose en casos del norte, centro y este de Europa, por lo que no resulta sencillo aplicarlo a los territorios de lengua catalana y vasca ${ }^{4}$.

«Renacimiento» es un término polisémico. En italiano, tal vez la lengua matriz, Risorgimento se refiere al proceso de unificación política de los diversos estados de la península itálica entre 1815 y 1871 . En otros idiomas, «renacimiento» significa más bien los esfuerzos por parte de la intelligentsia para cultivar la lengua de su comunidad lingüística, a menudo tras siglos de abandono administrativo. Ese sería, en principio, el caso de la Renaixença en los territorios de lengua catalana ${ }^{5}$ y del Rexurdimento en Galicia ${ }^{6}$. Otras veces, se ha tratado de combinar la "recuperación» de una lengua con el intento de expandirla a zonas donde ya no se hablaba o, incluso, donde no existe constancia de que

2 Una evaluación crítica del concepto de «renacimiento» literario entre los pueblos europeos sin estado en Marfany (2008).

3 Hroch (1985).

4 El propio Hroch (2000 y 2015) intentó extender su esquema al sur de Europa, incluidas Cataluńa, Vizcaya y, tal vez, Guipúzcoa, aunque no los otros territorios de lengua catalana y vasca.

5 La bibliografía sobre la Renaixença es inmensa. Una selección de títulos se cita a lo largo de este trabajo. Para el estudio de las fuentes me he servido de la recopilación de Molas et al. (1989).

6 Hermida (1992); Monteagudo (1999): 327-384, y Beramendi (2007): 155-162. 
se haya hablado nunca. El «renacimiento» del hebreo en Israel (Tehiiya) sería el prototipo de éxito de esta variante y el del gaélico en Irlanda (Athbheochan), el de fracaso 7 . Tampoco puede obviarse el hecho de que el «renacimiento» cultural suele mezclarse con reivindicaciones de "derechos históricos», muy presentes en el caso vasco (Pizkunde), por razones que se explicarán enseguida.

Como tantos conceptos que han triunfado a lo largo de la historia (Edad Media, Antiguo Régimen o Revolución industrial, sin ir más lejos), el de «renacimiento» suele ser una creación a posteriori, también en los casos de los que se ocupa este trabajo ${ }^{8}$. El «renacimiento» catalán tomó su nombre de la revista La Renaixensa, editada desde 1871 por la Jove Catalunya, tenida por la primera asociación catalanista9 ${ }^{9}$. Es decir, el nombre es 38 ańos posterior al supuesto origen del movimiento, que, de manera más que arbitraria, se ha situado en 1833, con la publicación de La Pàtria, de Carles Aribau ${ }^{10}$. Y es que en la elección de Aribau como patriarca de la Renaixença se entremezclaron razones políticas. Los representantes del primer catalanismo cultural, romántico y conservador, le otorgaron la primogenitura a causa de sus vínculos con el poder económico madrileño. Así que, por ejemplo, Antoni Puigblanch, otro de los posibles candidatos para ese título en el principado, que había escrito en catalán bastante antes de 1833, quedó descartado por su ideología radical ${ }^{11}$. Aribau compuso su oda en honor del marqués de Remisa, «uno de los financieros catalanes que en la villa y corte contribuían a la constitución del Estado español moderno, doctrinario y centralista $»^{12}$. Aribau, que fue director de la Biblioteca de Autores Españoles, debía de estar muy dotado para las lenguas, pues además de la Oda a la Pàtria escribió otros seis poemas en catalán y varios más en castellano, italiano y francés. Además, es el posible autor de un Discurso sobre la posibilidad de un idioma universal ${ }^{13}$. Pese a lo dicho, hoy 1833 es una fecha-tótem en Cataluña. La publicación de La Pàtria,

Un estudio en castellano sobre la Tehiya y la Athbheochan en Zabaltza (2006).

8 Curiosamente, Risorgimento sería la excepción a esta regla, ya que el vocablo aparece en una obra de Benvenuto Robbio di San Raffaele, de 1769, en la que se refiere no al pasado sino al esperado «renacimiento» literario italiano. Risorgimento (1949): 434.

9 Coromines (1980-1991): V, 903. Anteriormente, en castellano, la expresión «renacimiento» catalán se documenta en Rubió i Ors en 1859; Briz en 1860, y Almirall en 1868, entre otros. Gaietà Vidal utiliza renaixement en catalán ya en 1865 (Rossich, 1994; Domingo, 2009).

10 Rubió y Ors (1880): 164-165.

11 Grau y López (1988).

12 Sanchis Guarner (1974): 142.

13 Hina (1986): 119. 
un poema de circunstancias por un autor que no tenía ningún interés en la normalización de la lengua catalana, es aceptada de modo convencional como el fin de la Decadència, otro paradigma historiográfico ${ }^{14}$.

El origen de la Renaixença valenciana ha sido objeto de debate. Joan Fus$\operatorname{ter}^{15}$ y Manuel Sanchis Guarner ${ }^{16}$, entre otros, afirmaron que era hija de la catalana. Otros investigadores, como Vicent Simbor, han insistido en los vínculos del "renacimiento» literario valenciano con autores románticos locales que escribieron en catalán culto antes incluso de la fecha mítica de $1833^{17}$. Finalmente, Rafael Roca se ha decantado por una síntesis entre ambas posiciones al afirmar que el movimiento valenciano «fou, a la vegada, espontani i dependent de Catalunya. Espontani perquè ací, a València, ja hi havia tota una sèrie de precursors que esperonaven i facilitaven el correu literari valencià [...]. I dependent de Catalunya perquè fou en arribar Marià Aguiló [en 1858], que portava l'alé renaixencista català, qu'els esforços s'agruparen, es dotaren de contingut i prengueren $\cos ^{18}{ }^{18}$. Desde la obra de Fuster ${ }^{19}$ es un lugar común mencionar el fracaso de la Renaixença al sur del Cenia por su incapacidad para movilizar políticamente a la población valenciana. Como se tratará de exponer a lo largo de este artículo, solo se puede hablar de "fracaso» si se parte de una concepción teleológica que presuponga la obligatoriedad del paso de las reivindicaciones culturales a las políticas.

Respecto a las Baleares, a pesar de la importancia de figuras como el mencionado Aguiló, al que Pompeu Fabra, padre del catalán moderno, calificó como «el primer que va creure en la possibilitat de refer la nostra llengua ${ }^{20}$, el movimiento "renacentista» isleño fue una creación exclusivamente intelectual $^{21}$. Sea como sea, los autores de la parte espańola del dominio lingüístico catalán estaban en contacto continuo (los valencianos Llorente y

\footnotetext{
14 Rossich (1994).

15 Fuster (1977).

16 Esa era la postura de Sanchis Guarner en 1956. Hacia 1968, matizó esta opinión, poniendo de relieve la importancia de autores anteriores a Llorente, como Vicent Boix, que escribió casi toda su obra en castellano, y Tomàs Villarroya. Sanchis Guarner (1974) y Ferrando y Cortés (2007): 254-257 y 317-318.

17 Simbor Roig (1980). Para Simbor, Joan-Baptista Escorigüela, autor de varias poesías a finales del XVIII, sería el iniciador del movimiento, no solo en Valencia, sino en todo el dominio lingüístico.

18 Roca Ricart (2007): 92-93.

19 Fuster (1992): 221-234.

20 En Lamuela y Murgades (1984): 189.

21 Llull (1975) y Tomàs (2012a) y (2012b).
} 
Querol reconocían como maestros al catalán Rubió i Ors y al mallorquín Aguiló) y por eso se habla de una sola Renaixença y no de varios movimientos diferentes. Como afirmaba uno de los autores «renacentistas», Víctor Balaquer, en 1880: «El renacimiento de las letras lemosinas es uno, como una es la lengua $»^{22}$.

Diferente es el caso de la Renaixença rosellonesa, no solo por su debilidad (rasgo que comparte con la valenciana y la balear), sino porque se encuentra en un término medio entre el catalanismo cultural y el felibrismo, movimiento que defendía la "hipótesis lemosina», a la que alude Balaguer en la cita anterior, es decir, que el catalán era simplemente un dialecto occitano más. Desde la segunda mitad del siglo xIx esta teoría fue quedando en descrédito en Cataluña y en las Baleares (Balaguer es de sus últimos partidarios), pero se mantuvo en Occitania, en el Rosellón y en Valencia, donde serviría más tarde para justificar el secesionismo lingüístico valenciano ${ }^{23}$. Esta dicotomía catalana/occitana se deja traslucir, por ejemplo, en Justin Pépratx, uno de los contados poetas del norte de la Albera que participó en los Juegos Florales de Barcelona, miembro prominente del Felibritge en el Rosellón ${ }^{24}$. La Catalanofonía francesa será el pariente pobre en el «renacimiento» catalán. Justo lo contrario que la Vascofonía francesa en el vasco.

El término euskérico Pizkunde es un neologismo acuñado por Sabino Arana en 1896, pero hubo que esperar hasta los años 70 del siglo xx para que se concretara el ámbito temporal del «renacimiento» vasco. Por ejemplo, Joan Mari Torrealday colocó los límites cronológicos del Pizkunde en la abolición foral (1876) y en el inicio de la Guerra Civil (1936) ${ }^{25}$. Torrealday, que enmendaba el esquema establecido por el propagandista nacionalista Aitzol en los ańos $20^{26}$, intentó sentar los precedentes del resurgimiento en la vida pública de la lengua vasca tras cuarenta ańos de dictadura. Emuló para ello el concepto de Renaixença y lo aplicó a los territorios vascos, pero incluyendo autores (etnógrafos, lingüistas, agitadores políticos...) que escribían en castellano y en francés. Cabe añadir que, según la nueva acepción, convertida en clásica,

\footnotetext{
En Roca Ricart (2007): 164; cursivas suprimidas.

Rafanell (1991) y (2006).

Berjoan (2011): 88-91.

Torrealday (1977): 247-280.

José Ariztimuño Aitzol escribió sobre todo en castellano y no usó el término pizkunde, sino «renacimiento", con el que se refería al movimiento nacionalista vasco, supuestamente iniciado en 1882, ańo en el que Sabino Arana pretendía que su hermano Luis le había revelado que su patria era Vizcaya. Ariztimuño (19861988): 380-381.
} 
el Pizkunde sería casi medio siglo posterior a la Renaixença oficial. Situar el origen de aquel en 1876 tiene sentido si lo que se pretende es establecer una relación de causa-efecto con el Partido Nacionalista Vasco, cuyo germen vizcaíno se constituye solo diecinueve años más tarde, en 1895, en la transición de la fase A a la fase B de Hroch. Por el contrario, la fundación de la Lliga, el primer partido nacionalista catalán, se sitúa en 1901, una vez concluida la Renaixença, en la transición de la fase $\mathrm{B}$ a la fase $\mathrm{C}^{27}$.

Resumiendo. Según la historiografía catalanista tradicional, la Renaixença se produjo tras varios siglos de Decadència y ciento veinte años después de la abolición de las instituciones de la antigua Corona de Aragón, durante y tras la Guerra de Sucesión (1701-1715). Por el contrario, el Pizkunde, según la narrativa canónica, se inicia precisamente tras la abolición de los fueros de Álava, Guipúzcoa y Vizcaya, como consecuencia de la Tercera Guerra Carlista (1872-1876). (El movimiento iniciado en 1876 tuvo influencia también en Navarra, a pesar de que la ley del 21 de julio no incluía al Viejo Reino en su ámbito de aplicación). Ello explica que, frente a su homónimo en los territorios de lengua catalana, el «renacimiento» en la parte española de la Vascofonía sea un movimiento más basado en la reivindicación de la peculiaridad institucional que en la de la lengua privativa. Herederos de una tradición que se remonta incluso hasta el siglo XVI, la mayor parte de los autores fueristas ${ }^{28}$ escribirán en castellano, la lengua en la que funcionaban las instituciones vasco-españolas del Antiguo Régimen, a diferencia de las catalanas, valencianas y mallorquinas. Como trataré de exponer a continuación, colocar el inicio del Pizkunde en 1876, como hace la historiografía, vasca y no vasca, supone dejar de lado la importante tradición vasco-francesa, anterior y mucho más centrada en la lengua.

\section{JOCS FLORALS Y KOPLARIEN GUDUAK}

En los apartados que siguen matizaré la influencia que se atribuye a la Renaixença y el Pizkunde en la normalización de la lengua y en la formación del nacionalismo político. Soy muy consciente de la crítica a la misma idea de Renaixença por parte de historiadores recientes ${ }^{29}$. En este trabajo, este concepto, como el de Pizkunde, se utiliza como lo que es: un paradigma creado a

Brunn (1978): 294-296 y Puhle (1982).

28 Juaristi (1987); Sánchez Prieto (1993), y Rubio Pobes (2003): 254-331.

29 Marfany (1992), (1995), (2001) y sobre todo (2017); Archilés y Martí (2001), y Fradera (2003). 
posteriori que puede ser útil si no se toma en términos absolutos (ni el catalán ni el vascuence fueron nunca lenguas muertas, y por eso las palabras «renacimiento", «restauración» y semejantes aparecen entrecomilladas) y si se es consciente de las diferencias estructurales entre los dos dominios lingüísticos y entre territorios dentro del mismo dominio. Así, he hablado fundamentalmente de cultivo de la lengua privativa en Cataluña, Valencia, Baleares y Rosellón (también en la Vascofonía francesa, como se explicará) y de apelación a «derechos históricos» en Álava, Guipúzcoa, Vizcaya y Navarra. Como suele ocurrir, la historia real es mucho más compleja que cualquier caricatura y, al menos en Cataluña, con la politización del movimiento, se iniciará también la reivindicación de instituciones propias.

El idioma catalán nunca dejó de ser el habitual de la mayor parte de la población de su dominio lingüístico, incluidas sus clases dirigentes ${ }^{30}$. Una diferencia notable respecto a los territorios vascos, donde, al menos desde la industrialización, el castellano ha sido la lengua mayoritaria y la asimilación lingüística de sus élites es incluso anterior ${ }^{31}$. Si entendemos por Renaixença el proceso por el que el catalán, de ser una lengua fundamentalmente hablada se convirtió en una lengua también escrita considerada digna de un uso literario culto, mucho mayor trascendencia que La Pàtria tuvieron los juegos florales (jocs florals), iniciados una generación posterior al poema de Aribau. Como los movimientos análogos en otros lugares de Europa, el «renacimiento» del catalán y la "restauración" de los juegos florales, impulsados por intelectuales e industriales en parte castellanizados, coinciden con la generalización de la diglosia $^{32}$. Más adelante se insistirá en esta idea.

Aunque el nombre se generalizó mucho más tarde, los primeros juegos florales medievales tuvieron lugar en lengua occitana en Toulouse en 1324. En los siglos posteriores hubo certámenes literarios en la Catalanofonía y la Vascofonía ${ }^{33}$. Los juegos tolosanos, que, por lo menos, desde 1513 eran en francés, fueron interrumpidos por la Revolución, pero se restauraron (aquí sin comillas)

30 En Valencia la castellanización parcial de sus clases pudientes se retrotrae a las Germanías (1520-1522) y Ninyoles (1978): 49-50.

31 Según Erize Etxegarai (1997: 263), hacia 1863 los vascófonos suponían el 55 \% de la población en el conjunto de los territorios vascos. En aquella época hablaría vascuence el $96 \%$ de los guipuzcoanos, el $81 \%$ de los vizcaínos, el $65 \%$ de los vasco-franceses, el $30 \%$ de los navarros y el $10 \%$ de los alaveses. Con toda probabilidad este porcentaje había descendido por debajo del $50 \%$ para inicios del siglo xx, que es cuando se articula el nacionalismo político.

32 Marfany (2017).

33 Urkizu (1997): 11-12 y Rossich (2006). 
en 1806. A partir de ahí se ha pretendido que los juegos decimonónicos de los territorios de lengua catalana son una continuación del movimiento felibre de la Provenza, que, liderado por Frédéric Mistral, aspiraba a recuperar para la lengua de oc las glorias de los antiguos trovadores ${ }^{34}$. Sin embargo, una relación tan directa no es posible ya que, hasta inicios de la década de 1860 , catalanistas y felibres vivieron en un absoluto desconocimiento mutuo ${ }^{35}$. Además, bastante antes de 1854, que es cuando se constituye el felibrismo como tal, en concreto en 1842, la Real Academia de Buenas Letras había organizado en Barcelona un concurso literario, antecedente inmediato de los, ahora sí, juegos florales, que tuvieron lugar en la capital catalana desde 1859. La de Buenas Letras estaba en contacto con la Académie des Jeux Floraux de Toulouse, heredera directa del Consistòri del Gai Saber. Fue en el seno de la Academia barcelonesa, estimulada por el recuerdo de los juegos medievales, donde surgió la idea de «restaurarlos», sin que mediara influencia felibre ${ }^{36}$. La diferencia fundamental entre los nuevos juegos de los territorios de lengua catalana y los occitanos es que aquellos se celebraron (con la excepción parcial valenciana) en la lengua autóctona, mientras que en estos solo se utilizó el francés hasta 1895. Por eso los felibres, empeńados en revivir el provenzal, organizaron sus propios juegos desde 1862 y participaron en los de Barcelona hasta $1899^{37}$.

En la segunda mitad del siglo XIX se organizaron juegos florales en la mayor parte del dominio lingüístico catalán. En este artículo se prestará atención solo a los de Barcelona («restaurados» en 1859) y a los de Valencia (en 1879, con un precedente el mismo 1859), pero también los hubo al menos en Olot (1890), Castellón (1892), Lleida (1895), Alcoi (1899) y Torrent (1900) ${ }^{38}$. Contra lo que pudiera pensarse, en esta época no existió rivalidad literaria entre los certámenes de Valencia y Barcelona, ya que valencianos, catalanes y mallorquines participaban sin problema en ambos ${ }^{39}$.

Que los organizadores de los primeros juegos barceloneses no las tenían todas consigo queda patente en las archiconocidas palabras de uno de ellos, el

34 Sobre el felibrismo, Martel (2004) y Rafanell (2006).

35 Aramon i Serra (1985); Jorba (1989), y Balanzà (1989).

36 Fradera (2003): 88-94; Rossich (2006), y Freixes (2012).

37 Rafanell (2006): vol. 1, 176 y 358.

38 En Lleida y Girona hubo también certámenes literarios bilingües. Fuera del ámbito cronológico de este artículo, hubo juegos florales en el Rosellón desde 1924 (bilingües en catalán y francés) y, ocasionalmente, en las Baleares desde 1904. Pons i Pons (1998): 175-185; Tubino (2003): 272; Roca Ricart (2010a): 260; Berjoan (2011): 166-167, y Casacuberta (2012).

39 Roca Ricart (2010a): 187-227 y Tomàs (2012a). 
renombrado filólogo Manuel Milà i Fontanals: «S’havia parlat tres hores en català i ningú no havia rigut ${ }^{40}$. Porque los nuevos trovadores partían de una concepción plenamente diglósica de las relaciones entre el castellano y el catalán. Para la mayoría de ellos, procedentes de los mismos sectores industriales e intelectuales que estaban generalizando la diglosia, el catalán podría ser utilizado como lengua poética, pero el castellano seguiría siendo la lengua A en los demás ámbitos. Y es que en 1859 el único nacionalismo que existía al sur de la Albera era el español. De hecho, los temas abordados por los juegos barceloneses cabe encuadrarlos, hasta la última década del xix, dentro de la tradición patriótica española, con una clara connotación antifrancesa ${ }^{41}$. Los juegos valencianos, por su parte, además de por la reivindicación de la hermandad de los territorios de lengua «lemosina», se caracterizaron por la exaltación de la unidad española y la refutación constante de las acusaciones de separatismo ${ }^{42}$.

Desde 1851, en la Vascofonía francesa se organizaron también juegos florales (el nombre habitual en el vascuence de la época es koplarien guduak, literalmente, "combates de poetas»), de la mano del mecenas de origen suletino Antoine d'Abbadie d'Arrast. Ya se ha aludido a la vinculación de los jocs florals con la tradición trovadoresca de los países de oc. En cambio, d'Abbadie no tenía conciencia de estar «restaurando» los certámenes euskéricos del siglo XVII, por ejemplo. El origen remoto de los koplarien guduak radica en París, en territorio de lengua de oïl: en los premios a los estudios de filología establecidos por Volney en 1803. Un labortano, Jean-Pierre Darrigol, fue el ganador del premio en la edición de 1829 con un trabajo sobre gramática vasca. La intervención de Michel d'Abbadie, padre de Antoine, no fue ajena a este reconocimiento ${ }^{43}$. El interés filológico definirá los juegos de los territorios de lengua vasca, mientras que en los territorios de lengua catalana, con mayor o menor fortuna, primará la aspiración literaria.

Frente a los autores vasco-españoles, los vasco-franceses no se preocupaban por los «derechos históricos». Eso se debe al hecho de que ya en 1789, recién iniciada la Revolución, fueron abolidas las instituciones de todas las provincias francesas que aún las mantenían, incluidas las tres vascas, antiguos pays d'états, Labort, Baja Navarra y Sola (y el Rosellón, pays d'imposition), y nadie al norte del Bidasoa estaba interesado en restaurarlas. Por eso mismo considero excesivo hablar de «regionalismo» en las provincias vasco-francesas en la segunda mitad del xix. A mi juicio, sería más correcto hablar simplemente de

\footnotetext{
40 En Carmona (1967): 61, nota 1.

41 Marfany (1992).

42 Roca Ricart (2010a): 93-185.

43 Dassance (1922).
} 
«culturalismo» o, si prefiere la terminología de Anne-Marie Thiesse, de «nacionalismo francés regionalizado" ${ }^{44}$, porque lo que pretendían d'Abbadie y los suyos era conservar la lengua y cultura vascas, supeditadas a las francesas, sin que existiera ninguna reivindicación de autonomía, ni siquiera de creación de un departamento vasco, separando las tres provincias vasco-francesas del Bearne. A pesar de ello, al estar centrados en el cultivo de la lengua, los juegos florales de la Vascofonía francesa son (en principio) parangonables con los de la Catalanofonía. Versificadores vasco-españoles participaron en los koplarien guduak, que, desde 1879, se celebraron también en la Vascofonía meridional, así que se produjo cierta síntesis entre el fuerismo del sur del Bidasoa y el culturalismo del norte. En ese encuentro entre tradiciones diferentes cabe situar la obra de autores como el navarro Arturo Campión, líder de la Asociación Euskara, y el vizcaíno Resurrección María de Azkue, que llegaría a ser el primer presidente de la Academia de la Lengua Vasca ${ }^{45}$. La mayor parte de las composiciones de los juegos euskéricos son deliberadamente apolíticas, lo que no impide que dejen traslucir una visión muy conservadora y confesional de la sociedad vasca, hasta el punto de que los republicanos organizaron sus propias fêtes basques, que hicieron la competencia a las de d'Abbadie desde $1893^{46}$. Los koplaris que abordan temas identitarios lo hacen desde una perspectiva de "doble patriotismo» ${ }^{47}$ (vasco y francés o español), aunque algunos de ellos están muy cerca de posiciones etnonacionalistas vascas ${ }^{48}$. Por razones obvias (d'Abbadie, además de vasco, era muy francés), en los juegos vascos, a diferencia de los barceloneses, no hay lugar para la galofobia. Por su tradición literaria, desde mediados del siglo XVI, y por su peso demográfico, hasta la industrialización de Vizcaya a finales del xix, el influjo de la Vascofonía francesa en el Pizkunde es considerablemente mayor que el de la Catalanofonía francesa en la Renaixença: esta se produjo en un sentido sur-norte, mientras aquel lo hizo en el sentido norte-sur. Si existe un «renacimiento» de la lengua vasca, concepto ya de por sí cuestionable, 1851 constituye un punto de partida bastante más sólido que 1876.

44 Thiesse (2006). El matiz de «culturalismo» (debería ser «lingüisticismo», pero no existe la palabra) respecto a «nacionalismo regionalizado» es que este se puede aplicar a las más variadas comarcas, mientras que aquel lo reservo para los territorios con lengua privativa.

45 Arana Goiri tuvo sus más y sus menos con ambos. Sobre Campión, que escribió sobre todo en castellano, Zabaltza (2005): 243-263. Sobre Azkue, Kintana Goiriena (2008).

46 Goyhenetche (1993): 8.

47 Tomo la expresión de Fradera (2003): 59-155, y Rubio Pobes (2003): 153-177.

48 Por ejemplo, el vizcaíno Felipe Arrese y el guipuzcoano Claudio Otaegui. Urkizu (1997): 293-294, 298-300, 306-311 y 327-328. 
La existencia de juegos florales es un síntoma, no la prueba de un «renacimiento» literario. En el siglo XIX este tipo de certámenes se prodigó por todo el territorio espańol. Los primeros juegos florales celebrados en Espańa en época moderna tuvieron lugar en Madrid en 1841, a iniciativa del Liceo Artístico y Literario, que se adelantó unos meses a la Real Academia de las Buenas Letras de Barcelona ${ }^{49}$. Hubo juegos florales en Andalucía desde 1850, en Castilla la Vieja desde 1878, en Aragón desde 1893 y en el País Leonés desde 1901, todos ellos monolingües en castellano ${ }^{50}$. A pesar de las esperanzas que Eugenio de Ochoa y Francisco María Tubino habían depositado en las literaturas regionales ${ }^{51}$, estos juegos no vinieron acompañados de un «renacimiento» digno de ese nombre, que resultaba superfluo, al ser el castellano la lengua del Estado. En Galicia, por su parte, también se celebraron xogos florais (los primeros, bilingües como la mayoría, en 1861), pero no parece que fueran un elemento definitorio del Rexurdimento ${ }^{52}$. En todos estos certámenes se exaltaba la región de turno, dentro de España, y, en ese sentido, fueron vehículos de nacionalización en un país en el que en 1877, tras veinte ańos de vigencia de la Ley Moyano, dos terceras partes de la población eran analfabetas, proporción superada en los territorios de lengua catalana, aunque no en los de lengua vasca ${ }^{53}$. Al sur de los Pirineos, los juegos florales, incluidos, en un principio, los barceloneses, fueron un exponente tan palpable como inofensivo del «nacionalismo (español) regionalizado»" ${ }^{4}$.

Si nos fijáramos tan solo en las fechas de los juegos florales, parecería que el «renacimiento» es paralelo en los territorios de lengua catalana y vasca. Incluso podríamos pensar que el vasco (1851) se adelantó al catalán (1859), pero se trata de un espejismo. El consistorio de los juegos florales barceloneses tuvo desde sus inicios interés en fomentar una ortografía única ${ }^{55}$. Esa

49 Miracle (1960): 138-139 y Freixes (2012): 112-115.

50 Núńez Seixas (2001): 510; Tomàs (2012b): 39, y, sobre todo, Soria Andreu (2002).

51 Tubino (2003) y Domingo (2009).

52 Hermida (1992): 71 y 240-243; Monteagudo (1999): 355 y 365, y Beramendi (2007): $156-157$ y $293-297$.

53 Álava (30,39\% de analfabetos), Navarra (49,86 \%), Guipúzcoa (50,15\%), Vizcaya $(50,45 \%)$ y Barcelona $(56,80 \%)$ estaban ese año por debajo de la media. Girona (67,84\%), Tarragona (72,90\%), Lleida (75,06 \%), Palma de Mallorca (76,89\%), Valencia $(78,66 \%)$, Alicante $(79,86 \%$ ) y Castellón (81,56 \%), por encima. Espigado Tocino (1990).

54 Para el papel de la región en la nacionalización española, además de la bibliografía citada hasta el momento, pueden consultarse Núñez Seixas (2001) y (2012); Archilés y Martí (2002), y Archilés (2006).

55 Ensaig (1863). 
preocupación es casi inexistente en el caso de los organizadores de los juegos vascos ${ }^{56}$, ya que, por su propia fijación con los dialectos, no sirvieron de estímulo para crear una literatura de calidad, ni siquiera para establecer los rudimentos de una lengua literaria común ${ }^{57}$. Nada de esto ocurría por casualidad. Basta comparar los lugares elegidos para los certámenes. La Barcelona de 1859, que contaba por entonces con 220000 habitantes, no era solamente la capital de Cataluña, sino uno de los escasos núcleos industrializados de la península y la mayor ciudad de Europa occidental en la que se hablaba mayoritariamente una lengua distinta a la estatal ${ }^{58}$. Por su parte, Valencia, donde la castellanización era más palpable, tenía por entonces 90000 habitantes. Lo lógico es que en los territorios vascos se hubiera escogido como sede de los juegos a Pamplona, Vitoria, Bayona o Bilbao, las ciudades más pobladas a mediados del siglo XIX, pero el vascuence era en todas ellas muy minoritario. Urruña, sede de los juegos vascos entre 1851 y 1863 , era por entonces una población labortana de apenas 3600 habitantes. Este dato es representativo de la opción tomada por el «renacimiento» en los casos que estudiamos. Siendo como eran ambos movimientos conservadores y nostálgicos, en la Vascofonía fue un movimiento ruralista sin remisión, mientras que en la Catalanofonía dejaba la puerta abierta a las clases urbanas. Jean Oxalde, el ganador de los Juegos Florales vascos de 1851, era un guarda forestal y agente de aduanas, natural de Bidarray, un pueblecito de la Baja Navarra, de ideología bonapartista, por más señas, como el propio d'Abbadie. El ganador de la englantina d'or de los juegos de Barcelona de 1859, Damas Calvet, era un ingeniero industrial proveniente de una familia adinerada de Figueres que estaba al corriente de la literatura europea de su tiempo (fue precisamente él quien puso en contacto a Frédéric Mistral, líder de los felibres, con los primeros «renacentistas» catalanes).

56 Una de las excepciones se produjo en las fiestas euskaras de Durango, organizadas por el Ayuntamiento de la localidad (no por d'Abbadie) en 1886, que destinó un número del programa a un «Proyecto, bases y Reglamento de una Academia de la lengua Euskara, en completa armonía con los principios católicos», una vez más, en castellano. El número fue cubierto por el historiador carlista vizcaíno Arístides de Artiñano, cuya obra en lengua vasca es ignota y que sin ningún pudor reconocía haber escrito su opúsculo «á vuela pluma y con el solo objeto de que no quedara desierto el número del cartel literario». Artińano y Zuricalday (1886): «Advertencia», sin paginar.

57 Sarasola (1982): 136 y Rubio Pobes (2003): 281-294. Los juegos florales estaban incluidos en las fiestas euskaras, que reunían también concursos de ganado y todo tipo de actividades folclóricas y deportivas.

58 Véase Bairoch et al. (1988): 283. 
Los juegos florales en los territorios de lengua catalana, tanto en Barcelona como en Valencia, fueron una creación de élites educadas en castellano, lengua en la que se expresaban habitualmente por escrito, como prueba su correspondencia privada ${ }^{59}$. Élites, decía, castellanizadas en parte, pero que habían mantenido el catalán como lengua hablada y que como ideal literario pugnaban por un idioma culto, basado en la tradición medieval, un modelo inviable que habrá que modificar. Por el contrario, los juegos florales en los territorios de lengua vasca, donde la tradición literaria escrita y el recuerdo de un uso institucional del idioma privativo eran mucho más endebles, propugnaban una literatura popular, basada en el versolarismo ${ }^{60}$, con valor más antropológico que artístico, salvo honrosas excepciones. Ya se ha señalado que los juegos florales, catalanes, valencianos y vascos, iniciaron su andadura en el momento álgido de la diglosia. La diferencia crucial es que en la Catalanofonía la diglosia no dio lugar a la sustitución lingüística, como sí ocurriría en parte de la Vascofonía, donde, debido no solo pero también a los juegos florales y a las fiestas euskaras, el vascuence se identificó con el mundo rural, con lo que, implícitamente, se transmitió la idea de que no era adecuado para la vida urbana.

Los juegos barceloneses, monolingües en catalán, abrieron para la lengua catalana un resquicio en el espacio público más formal, que hasta entonces le había estado vedado casi por completo. Una generación después de los primeros juegos, la «recuperación» de la lengua iniciada por autores diglósicos (que habían optado por el monolingüismo no por motivos ideológicos, sino por fidelidad a la tradición medieval) se había mezclado con otro tipo de intereses. Dicho de otro modo: la lengua se "politizó». Hroch consignaría el paso de la fase A a la fase B. El monolingüismo de los juegos fue mudando paulatinamente en la exigencia del reconocimiento público de la lengua (en cambio en Valencia, donde dada la situación sociolingüística ya fue un logro que se optara por el bilingüismo y donde las élites se mantuvieron al margen de cualquier reivindicación de tipo político, no surgió reivindicación alguna en ese sentido). La Renaixença se posicionó a favor de la oficialidad exclusiva del catalán por lo menos desde 1883 y esa misma fue en 1892 la postura de las Bases de Manresa, uno de los hitos del incipiente catalanismo político ${ }^{61}$. A partir de entonces el catalán se fue introduciendo, no sin resistencias, en

59 Simbor Roig (1980): 13-17; Solà (1991): 146, y Anguera (1997): 41.

60 El versolarismo (bertsolaritza) es una técnica popular de versificación, normalmente improvisada, típica de la Vascofonía.

61 En cambio, el Centre Català, fundado por Almirall (1882) era favorable a la oficialidad compartida entre el castellano y el catalán. Llorens i Vila (1992): 83 y 172-173. 
diversas instituciones, privadas y públicas, empezando por el Ateneo Barcelonés en 1895 . Semejante demanda resulta inexistente hasta época mucho más reciente en la Vascofonía, dado que las clases pudientes se encontraban bastante más asimiladas lingüísticamente que las catalanas, por lo que el apoyo que decían dar al idioma tenía no poco de retórico (y eso que los juegos eran monolingües en vascuence ${ }^{62}$ ). Además, no hace falta caer en el purismo de los nuevos trovadores catalanes para entender que una lengua culta puede servir para la vida moderna y cuestionar (o no: ahí está el contraejemplo valenciano) la hegemonía del castellano y del francés. Lo que es seguro es que una lengua dialectalizada solo sirve para la vida doméstica y rural (y para certámenes literarios arcaizantes). Los nacionalismos respectivos serán herederos de esa posición de partida. Desde sus cargos de presidente de la Diputación de Barcelona y de la Mancomunidad Catalana, Enric Prat de la Riba apoyará la ortografía del Institut d'Estudis Catalans, que no era la suya (ni la de los juegos florales) ${ }^{63}$. Sabino Arana, por el contrario, será siempre contrario a la unificación del idioma y partidario de una literatura dialectal (en realidad, varias literaturas dialectales) y trató de imponer su peculiar ortografía ${ }^{64}$. La unificación ortográfica, que en la Catalanofonía se consiguió en 1913 gracias al apoyo del nacionalismo político, no se consiguió en la Vascofonía hasta 1968, en parte debido a la oposición del nacionalismo político.

Los jocs florals fueron reivindicados por Prat de la Riba como un precedente del nacionalismo catalán ${ }^{65}$. Por el contrario, Sabino Arana abominó de las fiestas euskaras, incluyendo los koplarien guduak, tildándolas de carnaval extranjerizante ${ }^{66}$. En las posturas de ambos existe una buena dosis de exageración, pero no dejan de ser significativas. El nacionalismo de Prat de la Riba pretendía ser la culminación de la Renaixença. Muy al contrario, el de Arana Goiri se presentaba en su retórica prometeica como una ruptura con prácticamente todo lo que había existido hasta entonces. No puede ser casualidad que el vocablo Pizkunde se documente por primera vez el 21 de septiembre de

62 Los juegos florales organizados por d'Abbadie en la Vascofonía francesa desde 1851 eran exclusivamente en vascuence y así lo siguieron siendo en la Vascofonía española desde 1879. Sin embargo, al sur de los Pirineos se prodigaron otros certámenes, que, con la excepción de los del Ayuntamiento de San Sebastián, solían combinar el vascuence y el castellano, incluso en zonas con un alto porcentaje de vascófonos monolingües. Dávila Balsera y Eizaguirre Sagardia (1995) y Toledo Lezeta (1998).

63 Balcells et al. (1996): 441-457.

64 Arana Goiri (1980) y Kintana Goiriena (2008): 459-479.

65 Prat de la Riba (2000): 610 y (2000): 124.

66 Arana Goiri (1980). 
1896, en el escudo de la sociedad Renacimiento de la Historia y la Lengua de Bizkaya, que es también el acta de nacimiento del más conocido de los neologismos sabinianos: Euzkadi ${ }^{67}$. Según Sabino Arana, el Pizkunde no empieza ni con los juegos florales ni con la abolición foral, sino con su propio concepto de Euzkadi. Y en esto radica la principal innovación del nacionalismo vasco respecto al culturalismo anterior. D’Abbadie y todos los koplaris habían cantado a Euskal Herria, («la Tierra del Vascuence», término documentado desde 1567). El Euzkadi de Sabino Arana, además de «la Tierra del Vascuence» incluía también zonas de Álava, Vizcaya y Navarra donde solo se hablaba castellano desde hacía siglos ${ }^{68}$. Su Pizkunde se aleja del de d'Abbadie y de la Renaixença, que actuaban exclusivamente en comarcas de lengua vasca y catalana, para situarse en un territorio indefinido entre la Athbheochan y la Tehiya.

Una última idea antes de acabar este apartado. El precio del esfuerzo por convertir el catalán en la lengua A, que solo tuvo recompensa, y muy tardíamente, en Cataluña, fue el aumento de la distancia sociolingüística respecto al catalán de los otros territorios, especialmente en Valencia, donde siguió siendo la lengua $\mathrm{B}$, con la aquiescencia de algunos autores jocfloralescos que se movían en una situación diglósica como pez en el agua. Desde la irrupción del catalanismo político, el «valenciano» es, sociológicamente hablando, una lengua diferente del "catalán» («sociológicamente», no desde el punto de vista filológico). En los territorios vascos no ocurrió este fenómeno, porque todos, incluidos los nacionalistas, a pesar de declaraciones en sentido contrario, se resignaban a que el vascuence fuera la lengua $\mathrm{B}$, supeditada al castellano o al francés. En ese sentido, el nacionalismo vasco constituye una anomalía, al menos si se le compara con sus homónimos del este, centro y norte de Europa, e incluso con Flandes, los casos estudiados por el primer Hroch, dado que uno de los objetivos prioritarios de los nacionalismos sin Estado suele ser colocar la lengua privativa por lo menos en un nivel de igualdad respecto a la lengua estatal ${ }^{69}$.

\section{CULTURALISMO, PROVINCIALISMO Y REGIONALISMO}

Todos los «renacimientos» objeto de estudio de este trabajo fueron en un principio subproductos del «nacionalismo regionalizado», español y francés.

67 En la última página de su obra Lecciones de ortografía del euskera bizkaino. Arana Goiri (1980): 982.

68 Zabaltza (2005): 23-33.

69 Hobsbawm (1991): 120-128, y Hroch (2000): 83-84 y (2015): 215-217. 
Pero la Renaixença demostró el potencial de la lengua privativa, lo que, sumado a la apuesta de las élites catalanas por esta lengua (que, a pesar de la diglosia, nunca había dejado de ser la suya), imprimirá un carácter lingüístico muy marcado al nacionalismo catalán, del que carece el nacionalismo vasco, por ejemplo. Y en Cataluña tampoco fue todo un camino de rosas. Fue un proceso lento, muy minoritario al principio, que pudo no haberse dado, como en Valencia, Baleares y Rosellón, donde, para bien y para mal, la lengua no se "politizó». Por dar un dato, en 1887, más de medio siglo después del inicio oficial de la Renaixença, de los 183 periódicos de Cataluña solo 15 se publicaban en catalán ${ }^{70}$. Eso es muy significativo, no solo por el papel desempeñado por la prensa para «imaginar» la nación ${ }^{71}$, sino porque únicamente podemos hablar de nacionalismo catalán cuando el objetivo es la normalización de la lengua en todos los ámbitos de la vida cotidiana, no su mera supervivencia en una situación diglósica, como habían pretendido los jocfloralescos y, en general, los primeros catalanistas. El catalanismo político solo se impondrá tras la Renaixença, vinculado a movimientos como el Modernisme y el Noucentisme y, por supuesto, ya se ha apuntado, a la opción de las élites y al dinamismo económico y social de Barcelona.

No cabe duda de que se produjo un «salto» entre el «renacimiento» catalán y el nacionalismo posterior, que incorporó la idea de que España era solo un Estado ${ }^{72}$. Ese salto es todavía más abrupto entre el Pizkunde iniciado en 1851 y el nacionalismo vasco, ya que a la discontinuidad ideológica hay que añadir la lingüística. La Renaixença no fue, ni mucho menos, una condición suficiente para el surgimiento del catalanismo político, pero sí una condición necesaria. Y aclaro que entiendo por catalanismo político una ideología plural en constante evolución, más amplia que el nacionalismo, y con un enorme potencial de amalgama social. Porque el catalanismo albergó en su seno varias tendencias, a menudo contrapuestas entre sí. Tan catalanista era el federalista Almirall como el nacionalista Prat de la Riba. No se puede concluir que la Renaixença, iniciada (supuestamente) en 1833, anunciaba ya la Lliga, creada casi setenta años después. Como reduccionista resulta identificar la Lliga con todo el catalanismo, cuando este partido, en cuya formación participaron elementos empresariales que no habían participado en el «renacimiento» literario $^{73}$, nunca consiguió aglutinar al conjunto del movimiento. Solo Solidaritat Catalana (1906-1909), a la que, además de la Lliga, se sumaron nacionalistas

\footnotetext{
Figueres (1986): 80.

Anderson (1991): 24-25.

Marfany (1992), (1995), (2001) y (2017).

Riquer (1977): 305-310 y 331-334.
} 
de otras tendencias, carlistas y republicanos, fue capaz de reunir a todos los catalanistas durante una breve coyuntura. Claro que, a partir de Solidaritat, el catalanismo se convierte en un movimiento de masas en Cataluña. Es la fase C de Hroch.

Si no resulta sencillo vincular los «renacimientos» literarios con movimientos nacionalistas, en ocasiones ni siquiera se pueden establecer concomitancias con movimientos regionalistas. Ya se ha hablado del Pizkunde vasco-francés. También el prócer del sector cultista de la Renaixença valenciana, Teodoro Llorente, puso un gran empeño en evitar la politización del movimiento en Valencia. El valencianismo, para él, se limitaba a cultivar la lengua valenciana o catalana (él utilizaba ambas denominaciones sin problema $^{74}$ ) según patrones arcaizantes. La creación de un partido no ya nacionalista sino simplemente regionalista quedaba por completo descartada. Por eso sería más exacto tildar a la Renaixença valenciana de movimiento culturalista, más que regionalista, ya que en ningún momento pretendió recuperar las instituciones abolidas por los Borbones a principios del siglo XVIII, ni crear otras nuevas. Se trata este de un aspecto fundamental que lo distingue de su homónima catalana. Obvia añadir que esa oposición a la politización no impidió a Llorente ser dirigente del Partido Conservador y diputado y senador por esta formación. La Renaixença valenciana, que incluía también un sector más popular en torno a Constantí Llombart, no pasó de ser un movimiento de la intelligentsia. El propio Llorente era consciente de la diferente evolución que estaban tomando los acontecimientos en Cataluña y en Valencia cuando, no sin cierta aprehensión, constataba ya en 1885 que "la diferènsia de criteri entre los trovadors valencians, que al llohar les glòries de nostre antich Reyne no aspiren a restablir-lo, en dany de la unitat espanyola, y els trovadors catalans — molts d'ells, si no tots - que trevallen per l'autonomia de Catalunya ${ }^{75}$. València Nova y las diversas asociaciones que surgirán desde principios del siglo $\mathrm{xx}$ intentarán en vano transformar el valencianismo cultural en un movimiento autonomista sólido ${ }^{76}$. El valencianismo nunca superó la fase $\mathrm{B}$ de Hroch. Por su parte, en las Baleares y en el Rosellón, las agrupaciones con veleidades políticas (regionalistas y nacionalistas) fueron débiles e inconsistentes $^{77}$. Es decir: ambos territorios se quedaron en la fase A. Cataluña, el único territorio de la Catalanofonía en el que las reivindicaciones culturales fueron con éxito de la mano de las políticas, es la excepción, no la regla.

\footnotetext{
74 Roca Ricart (2010b): 45-46.

75 Llorente (2013): 151.

76 Cucó (1999): 69-71.

77 Llull (1975); Pons i Pons (1998); Carrió i Trujillano (1999), y Berjoan (2011).
} 
En el caso vasco, el aranismo, que fue la forma de nacionalismo que triunfó, no surgió del «renacimiento» literario previo, fundamentalmente vasco-francés y «apolítico», sino de los autores fueristas vasco-españoles (e incluyo entre ellos a los llamados «apologistas del vascuence», como Astarloa $)^{78}$, que se expresaban casi exclusivamente en castellano. Como la mayor parte de los «bizkaitarras», Sabino Arana era en origen castellanohablante y su conocimiento de la literatura euskérica no pasaba de superficial. El catalanismo tuvo una base social amplia y heterogénea, entre otras razones porque partió de una situación sociolingüística relativamente halagüeña, dado que todas las clases autóctonas y parte de las de origen inmigrante eran catalanohablantes. El nacionalismo vasco surgió en el ambiente castellanohablante de Bilbao en la mente de un líder carismático, que reinterpretó en clave independentista los postulados fueristas y, obvia decirlo, no contó con el apoyo de movimientos análogos al Modernisme o al Noucentisme. En contraste con los miembros de la patronal catalana que confluyen en la Lliga en 1901, la mayoría de los antiguos partícipes de la Sociedad Euskalerria, fueristas intransigentes seguidores del empresario naviero Ramón de la Sota que ingresaron en el PNV desde 1898, estaban todavía más castellanizados que Arana Goiri y algunos de ellos concedían más viabilidad al "dialecto bilbaíno» (un castellano salteado de palabras euskéricas) que al vascuence ${ }^{79}$. Para el primer nacionalismo vasco el fundamento de la nacionalidad no será la lengua, sino la propia voluntad de diferencia. El radicalismo y el racismo de su discurso (compatibles con una praxis política regionalista) solo en parte disimulan ese voluntarismo.

Anteriormente he afirmado que el primer nacionalismo vasco no tuvo interés en crear una lengua literaria común. Sin embargo, faltaría a la verdad si no matizara que, desde el inicio, el nacionalismo contribuyó de modo significativo, si no a la normalización, sí al menos a la dignificación de la lengua vasca, lo que queda de manifiesto en un cierto aumento de la producción bibliográfica. En la etapa del Pizkunde anterior al nacionalismo (1850-1895) se publicaron anualmente quince libros en vascuence. En la posterior (18961935) fueron veinticinco anuales ${ }^{80}$. El nacionalismo fue un factor en la

\footnotetext{
Madariaga Orbea (2008).

79 Juaristi (1999) y Corcuera Atienza (2001): 493-571. Sota financió, entre otros proyectos, el que, es considerado como el primer periódico vasco-espańol íntegramente en la lengua privativa, Euskalzale, dirigido por Azkue (Bilbao, 1897-1899). Kintana Goiriena (2008): 394-399.

80 Entre 1876 y 1895 se publicaron 403 libros en lengua vasca, unos 20 por año. Entre 1896 y 1935 fueron 1019 libros, unos 25 por año. Entre 1850 y 1875, coincidiendo con los juegos florales vasco-franceses, aparecieron 309 libros, unos 12 por año.
} 
socialización de la lengua, bastante más determinante de lo que inducen a pensar las frías cifras. El nacionalismo es a la vez causa y efecto del Pizkunde y, de hecho, compite con él. La fase A es anterior, contemporánea e incluso posterior a la fase B.

Otra cuestión en la que hay que incidir es que la literatura fuerista, expresada en castellano, reivindicaba, más que la lengua privativa de los vascos, su tradición institucional. Pero esa tradición se enfrentaba al hecho de que en el Antiguo Régimen cada uno de los territorios vascos tenía sus propios fueros y era autónomo respecto a los demás. Salvados tres años de ocupación napoleónica (1810-1813) nunca había existido una entidad civil que englobara a Álava, Guipúzcoa y Vizcaya y, menos aún, a Navarra ${ }^{81}$ (en cambio, Cataluña y Valencia no fueron divididas en provincias hasta 1833). Así que el Pizkunde vasco-español tendía a ser más provincialista que regionalista. A la inversa, las provincias vasco-francesas sí que formaban, desde 1790, una unidad administrativa (junto al Bearne): el Departamento de los Bajos Pirineos. Sin embargo, al norte del Bidasoa no se reivindicó de modo explícito la creación de una región vasca hasta la Segunda Guerra Mundial ${ }^{82}$. Así que, hablando con propiedad, antes de la aparición del nacionalismo, no existió regionalismo en la Vascofonía, sino culturalismo y provincialismo, que, como mucho, aspiraba a una laxa confederación de los territorios vascos. El propio Sabino Arana, que fue albacea del fuerismo intransigente, se dio a conocer en 1892 con un libro titulado significativamente Bizkaya por su independencia y no, por ejemplo, Euskeria por su independencia. En 1898, siendo diputado provincial de Vizcaya, propuso la constitución de un Consejo Regional con representantes de Álava, Guipúzcoa, Navarra y Vizcaya para guiar a las cuatro diputaciones en las negociaciones con el poder central y sugerir actuaciones de interés común ${ }^{83}$.

Antes de 1850 se habían publicado 414 libros en vascuence, es decir, apenas 1,3 por año. Torrealdai (1997): 68, 91 y 115. Que sepa, no existe una recopilación tan exhaustiva de la producción bibliográfica de lengua catalana como la que Torrealdai ha realizado de la de lengua vasca, por lo que no he podido realizar una deseable comparación en este ámbito entre los dos dominios lingüísticos.

81 Entre 1775 y 1936 existieron las llamadas Conferencias Políticas, que reunían a los representantes de Álava, Guipúzcoa y Vizcaya y en las que participaron también los de Navarra desde 1897. Agirreazkuenaga (1995).

82 Jacob (1994): 107. El movimiento eskualerrista, activo en los años treinta, no se posicionó claramente por la creación de un departamento vasco. Larronde (1994). En el Rosellón no se produce la reivindicación de un departamento catalán, cuyos límites coincidirían con los de los Pirineos Orientales, con la mera supresión de la comarca languedociana de la Fenolleda.

83 Arana Goiri (1980). 
Sabino Arana, nacionalista radical en teoría, fue, en la práctica, uno de los primeros regionalistas que superó el tradicional provincialismo vasco-español. Y aun así nunca llegó a exigir la creación de algo parecido a un Gobierno vasco, reivindicación que solo se documenta durante el fracasado proceso autonómico de 1917-1919, cuando ya existía una Mancomunidad Catalana ${ }^{84}$. Valga ese dato para ilustrar el diferente grado de conciencia «nacional» de las provincias vascas y Cataluña.

Los «renacimientos» literarios se manifiestan en todos los territorios en los que se habla la lengua que se pretende «revivificar». Fueron los autores «renacentistas» los que crearon y divulgaron los símbolos identitarios de todo el dominio lingüístico, que, mucho más tarde, serían reinterpretados como símbolos pan-nacionalistas. Por ejemplo, Jacint Verdaguer, el autor de L'Atlàntida (1877), obra españolísima y cumbre de la Renaixença, convirtió en 1888 el Pi de les Tres Branques (Pino de las Tres Ramas), en Berga, que hasta entonces era contemplado como una representación de la Trinidad, en el símbolo de la unidad del Cataluña, Valencia y Baleares ${ }^{85}$. El lema Zazpiak $B a t$ (las siete son una), que simboliza la unidad de las provincias vascas de España y Francia, se expandió a toda la Vascofonía desde los Juegos Florales de Iurreta (1891) y San Juan de Luz (1892) ${ }^{86}$. Aunque pueda sorprender desde la perspectiva actual, ni el Pi de les Tres Branques ni el Zazpiak Bat eran en un principio símbolos nacionalistas y podían, por tanto, ser asumidos por quienes en la Catalanofonía o en la Vascofonía se sentían españoles y franceses.

Los activistas de los «renacimientos» literarios entendían a España (o, en su caso, a Francia) como una nación plurilingüe. Dado que en un principio no se dudaba de la hegemonía de la lengua castellana (o francesa) ni de la unidad política del Estado español (o francés), la fraternidad de Cataluña, Valencia, Baleares y Rosellón por una parte o la de Álava, Guipúzcoa, Vizcaya, Navarra y la Vascofonía francesa, por otro, no suponía ningún problema, ni para las élites locales ni para las de Madrid (ni para las de París), como simboliza la inauguración de la Gran Fiesta de la Tradición del Pueblo Vasco de San Sebastián por la familia real al completo (1904), ante los escudos de las

\footnotetext{
84 Belausteguigoitia (1918).

85 Verdaguer (1974): 413.

86 En Iurreta se documenta un poema, de autoría anónima, en el que en acróstico se lee: «Zazpiak beti bat» (las siete son siempre una). Urkizu (1997): 373 y Altzibar (1998). El lema, ya sin el beti, fue incluido en el escudo de las siete provincias de la Vascofonía en los juegos de San Juan de Luz, entre otros, en un cartel editado por Jules Mesnard (Imp. Belfond \& Cie, Paris).
} 
provincias vascas de Espańa y Francia ${ }^{87}$. O, por dar un ejemplo mucho más conocido, la lectura en catalán por parte de Menéndez Pelayo, discípulo de Milà i Fontanals, del discurso de mantenedor de los Juegos Florales de Barcelona de 1888, en presencia de la Reina Regente ${ }^{88}$. Porque catalanes y vascos no eran los únicos que aceptaban, con mayor o menor convencimiento, el plurilingüismo español, al menos en el plano literario ${ }^{89}$. Cuando se pretenda acabar con el monopolio del castellano en el ámbito administrativo, lo que solía ir parejo a la reivindicación de la autonomía o incluso la independencia, la actitud de estas élites cambiará por completo. El castellano, que hasta entonces había sido solo un elemento implícito del nacionalismo español, se convertirá en definitorio ${ }^{90}$. Los «renacimientos» culturales, en tanto que no cuestionaban el statu quo lingüístico, podían ser aceptables para el régimen de la Restauración (también para el Segundo Imperio e incluso, a pesar de su laicismo y su política educativa, para la Tercera República); los nacionalismos políticos, sobre todo el catalán, no.

De manera paradójica, los nacionalismos periféricos pondrán en un segundo plano la unidad cultural que los «renacimientos» habían proclamado. En parte debido al abandono de los sabinianos, la asociación Eskualzaleen Biltzarra (1902), heredera del culturalismo de d'Abbadie y cuyo ámbito de actuación eran las siete provincias de la Vascofonía, pronto dejó de funcionar al sur de los Pirineos ${ }^{91}$. Por su parte, las primeras organizaciones políticas catalanistas tendrán más interés en fomentar la unidad de acción entre catalanes, vascos y gallegos frente a Madrid que la hermandad con Valencia y Baleares, territorios que, por la debilidad del particularismo, empezaban a ser considerados como una carga en la lucha por la autonomía $a^{92}$.

Al explicar la aparición de los nacionalismos periféricos en España se suele incidir en la pérdida de lo que quedaba del Imperio en 1898. Es indudable que el «Desastre» de 1898 repercutió en la expansión de los nacionalismos catalán y vasco (originariamente solo vizcaíno). Pero por sí solo no explica el éxito de estas ideologías, porque también en Álava, Navarra, Valencia y Baleares hubo un 98, pero en estos territorios el nacionalismo alternativo al español

Aizpuru (2000): 100.

88 La visita real y la oposición a la Exposición Universal motivaron el boicot de Almirall y los republicanos, que organizaron unos juegos alternativos. Pinyol i Torrents (2012).

89 Mainer (2002) y Domingo (2009).

90 Núñez Seixas (2013).

91 Goyhenetche (1993).

92 Llorens i Vila (1992): 230-231. 
fue mucho más débil, cuando no inexistente. Incluso, en algún caso, dará lugar a regionalismos espańolistas opuestos a los nacionalismos periféricos. Si para Cataluña y Vizcaya (solo posteriormente, también para Guipúzcoa) puede servir, con matices, el esquema tripartito de Hroch, para los demás territorios espańoles (y franceses) con lengua privativa, resulta mucho más convincente la parábola del perro silencioso de Ernest Gellner ${ }^{93}$. Según el modernista Gellner, quien, frente a la actitud más matizada de su compatriota Hroch, insistió en la estrecha vinculación de la industrialización con el surgimiento de las naciones, solo una minoría de las comunidades lingüísticas desarrollan movimientos nacionalistas, es decir, «ladran». Los hechos diferenciales «objetivos», como la lengua, no generan por sí solas reivindicaciones políticas. Son los intereses económicos y la actitud de las élites ligadas a estos los que resultan determinantes.

Una de las elaboraciones teóricas que facilitó el paso al nacionalismo fue la hipótesis del relativismo lingüístico, según la cual la mentalidad de un individuo o de un colectivo viene determinada por la lengua en que se expresa ${ }^{94}$. Desde principios del siglo XIX, esta hipótesis, que, a pesar del éxito que ha conocido, dista mucho de haber sido demostrada, sirvió como argumento para los movimientos nacionalistas del centro y del este de Europa al presuponer que pueblos con lenguas diferentes tenían mentalidades diferentes y que, por tanto, precisaban de leyes diferentes para gobernarse. Dicho de otro modo: se identificó «nación» con "lengua», por lo que no podían existir naciones plurilingües. Entre los nacionalismos periféricos hispánicos fue el catalán el que más uso hizo de esta hipótesis (y eso que valencianos, baleares y roselloneses no parecían tener la misma mentalidad que los catalanes). Es cierto que entre los primeros catalanistas algunos, como Víctor Balaguer, añoraban, al menos retóricamente, la antigua Corona de Aragón y otros, como Manuel Duran i Bas, imbuido del espíritu de la Escuela Histórica del Derecho, colocaban al derecho privado catalán por encima de la lengua entre los elementos constituyentes de la nacionalidad. Pero estas tendencias historicistas, comunes por otra parte a todos los regionalismos (y culturalismos) europeos, quedaron superadas en Cataluña desde la década de 1880, con la constitución de las primeras asociaciones políticas catalanistas. El aranismo, que no se interesó por lo que ocurría fuera de los límites de Euzkadi, prefirió, en cambio, recurrir a una supuesta «raza» en la que cabían por igual hablantes de castellano, de francés y de vascuence. Eso tampoco ocurrió por casualidad.

93 Gellner (1983): 64.

94 Zabaltza (2006): 165-188. Llobera (1983) ha estudiado la influencia del concepto de Volksgeist, idea hermana del relativismo lingüístico, en el catalanismo. 
Tradicionalmente, los vascófonos constituían en los territorios vascos una minoría en términos cualitativos, ya que tendían a ocupar los estratos sociales inferiores, pero, desde la industrialización de finales del XIX, que, paradójicamente, es cuando surge el nacionalismo, fueron, además, una minoría en términos cuantitativos. Por si fuera poco, para entonces partes del país, incluidas muchas zonas urbanas, estaban castellanizadas (o francesizadas). Para la mayoría de los primeros nacionalistas vascos, la lengua privativa fue mucho más un símbolo que un medio de comunicación. Solo en la medida en la que el nacionalismo se expandió a zonas de lengua vasca fue incorporando una concepción más lingüística y menos racial de lo vasco ${ }^{95}$. Una victoria parcial de Azkue y Campión sobre Arana Goiri. En cambio, los nacionalistas catalanes tuvieron claro desde el principio que la lengua, hablada por todos los estamentos sociales, por todos los sectores ideológicos y en toda Cataluña (salvo el Valle de Arán), era el fundamento de la nacionalidad. De hecho, si existe en la periferia de Espańa un nacionalismo que se aproxime a su tipología oriental, mal llamada «étnica», ese es el catalán.

\section{CONCLUSIONES}

Hroch concibió su esquema tripartito partiendo de los «movimientos nacionales» surgidos en el norte, centro y este de Europa, varios de ellos en imperios multiétnicos. Él mismo intentó más tarde ajustar el enfoque al abordar casos del sur del continente, cuya estructura política es el Estado nación. Admitiendo que en toda tipología existe cierta dosis de arbitrariedad, el paso de la fase A (interés académico) a las fases B (agitación patriótica) y C (movimiento de masas) puede ser reconocido en Cataluña si se entiende por national movement no "nacionalismo catalán», sino "catalanismo político», que es algo bastante más amplio. Este esquema no es aplicable a los demás territorios de la Catalanofonía, a los que Hroch no presta ninguna atención. En el suroeste de Europa, la transición del «renacimiento» al nacionalismo se nos muestra como la excepción, no como la regla. La apuesta decidida de un sector de las élites, que solo una generación antes se decantaban por la diglosia, y el peso de Barcelona, una urbe de lengua catalana, tuvieron mucho que ver con esa excepcionalidad. El nacionalismo solo surge cuando las expresiones culturales se entremezclan con intereses económicos, normalmente en sociedades industriales. Una diferencia cultural o lingüística no tiene por qué crear reivindicaciones políticas, como lo prueban no solo Valencia, Baleares y el

95 Véase, por ejemplo, sobre Guipúzcoa, Aizpuru (2000). 
Rosellón, sino también Álava, Navarra y el País Vasco Francés (por no hablar de Occitania), territorios de industrialización tardía en los que el «perro silencioso» de Gellner se impone al esquema de Hroch. La peculiaridad de Guipúzcoa y Vizcaya, sobre todo de esta última, donde las clases que servirán de sostén al nacionalismo estaban castellanizadas en gran medida, es que el perro ladró, pero no en la lengua que cabía esperar.

Los nacionalismos políticos pueden dotar de consistencia a los «renacimientos» literarios. Aunque Hroch no insiste en este punto, la influencia entre ambas etapas es biunívoca (la fase A repercute en las fases $\mathrm{B}$ y $\mathrm{C}$, pero las fases $\mathrm{B}$ y $\mathrm{C}$ siguen influyendo en la fase A). Muy a menudo, es el nacionalismo el que ha creado reivindicaciones culturales y no a la inversa. Los nacionalismos suelen invocar los «renacimientos» como precedentes, ya que en ellos encuentran su justificación histórica, obviando el hecho de que las únicas naciones de los «renacentistas» eran España y Francia.

Pero más allá de estas disquisiciones eruditas, los «renacimientos» literarios nos retrotraen a una época en la que los diversos territorios españoles no habían sido «imaginados» todavía como monolingües. Aunque fuera en términos diglósicos, catalanes y vascos coincidían en que la lengua castellana formaba parte de su legado y muchos que no eran catalanes y vascos asumían el carácter plurilingüe de la monarquía espańola. Los nacionalismos (tanto los periféricos como el central) debilitaron esta manera de entender a Espańa y a sus pueblos.

\section{Bibliografía}

Agirreazkuenaga, J. (dir.). (1995). La articulación politico-institucional de Vasconia: Actas de las Conferencias formadas por los representantes de Álava, Bizkaia, Gipuzkoa y eventualmente de Navarra (1775-1936). Bilbao: Diputación Foral de Bizkaia.

Aizpuru, M. (2000). El Partido Nacionalista Vasco en Guipúzcoa (1893-1923). Orígenes, organización y actuación politica. Bilbao: Universidad del País Vasco.

Altzibar, X. (1998). 'Zazpiak Bat' gaia XIX. mendean. En Antoine d’Abbadie (1897-1997), Congrès International (pp. 663-688). Bilbao, Donostia: Eusko Ikaskuntza, Euskaltzaindia.

Anderson, B. (1991) [1983]. Imagined Communities. Reflections on the Origin and Spread of Nationalism. London, New York: Verso.

Anguera, P. (1997). El català al segle XIX. De llengua del poble a llengua nacional. Barcelona: Empúries.

Aramon i Serra, R. (1985). Frederic Mistral i la Renaixença catalana. Barcelona: Rafael Dalmau Editor.

Arana Goiri, S. (1980) [1896]. Lecciones de ortografía del euskera bizkaino. En S. Arana Goiri. Obras completas, vol. 2 (pp. 810-982). San Sebastián: Sendoa. 
- (1980) [1897]. Las Fiestas Euskaras. En S. Arana Goiri. Obras completas, vol. 2 (pp. 1256-1259). San Sebastián: Sendoa.

(1980) [1898]. Proposición de Sabino Arana siendo diputado. En S. Arana Goiri. Obras completas, vol. 3 (pp. 2396/1-2396/3). San Sebastián: Sendoa.

Archilés, F. (2006). 'Hacer región es hacer patria'. La región en el imaginario de la nación española de la Restauración. Ayer, 64, 121-147.

— y Martí, M. (2001). Satisfaccions gens innocents. Una reconsideració de la Renaixença valenciana. Afers, 38, 157-178.

- (2002). Un país tan extraño como cualquier otro: la construcción de la identidad nacional española contemporánea. En M. C. Romeo e I. Saz (eds.). El siglo XX. Historiografía e historia (pp. 245-278). Valencia: Universitat de València.

Ariztimuńo, J. (1986-1988) [1921]. La muerte del euskera o los profetas del mal agüero. En J. Ariztimuño. Obras completas, vol. 1 (pp. 335-388). San Sebastián: Erein.

Artiñano y Zuricalday, A. de (1886). Proyecto de Academia Bascongada. Barcelona: Establecimiento Tipolitográfico de los Sucesores de N. Ramírez y Compañía.

Bairoch, P., Batou, J. y Chèvre, P. (1988). La population des villes européennes de 800 à 1850. Banque de données et analyse sommaire des résultats. Genève: Centre d'Histoire Économique Internationale de l'Université de Genève.

Balanzà, E. (1989). Relacions entre escriptors occitans rodanians i escriptors dels Països Catalans (1860-1900). En A. M. Badia i Margarit y M. Camprubí (eds.). Actes del Vuitè Col.loqui Internacional de Llengua i Literatura Catalanes, vol. 1 (pp. 365-386). Barcelona: Associació Internacional de Llengua i Literatura Catalanes, Abadia de Montserrat.

Balcells, A., Pujol, E. y Sabater, J. (1996). La Mancomunitat de Catalunya i l'autonomia. Barcelona: Institut d'Estudis Catalans.

Belausteguigoitia, R. de (1918). Las bases de un gobierno nacional vasco. Bilbao: Imp., Lit. y Enc. Viuda e Hijos de Grijelmo.

Beramendi, J. (2007). De provincia a nación. Historia do galeguismo político. Vigo: Xerais.

Berjoan, N. (2011). L'identité du Roussillon (1780-2000): penser un pays catalan à l'âge des nations. Canet: Trabucaire.

Brunn, G. (1978). Die Organisationen der katalanischen Bewegung (1859 bis 1923). En Th. Schieder y O. Dann (eds.). Nationale Bewegung und soziale Organisation, vol. 1 (pp. 281-571). München, Wien: Vergleichende Studien zur nationalen Vereinsbewegung des 19. Jahrhunderts in Europa.

Carmona, Á. (1967). Dues Catalunyes. Jocfloralescos i xarons. Barcelona: Ariel.

Carrió i Trujillano, B. (1999). El nacionalisme a les Balears (1898-1936). Palma de Mallorca: Documenta Balear, Caixa de Balears, Consell de Mallorca.

Casacuberta, M. (2012). Els certàmens floralescos en el procés de construcció de la cultura del catalanisme: els casos de Girona, d'Olot i de l'Empordà. En J. M. Domingo (ed.). Joc literari $i$ estratègies de representació. 150 anys dels Jocs Florals de Barcelona (pp. 403-435). Barcelona: Societat Catalana de Llengua i Literatura.

Corcuera Atienza, J. (2001). La patria de los vascos. Orígenes, ideología y organización del nacionalismo vasco (1976-1903). Madrid: Taurus.

Coromines, J. (1980-1991). Diccionari etimologic i complementari de la llengua catalana. Barcelona: Curial. 
¿DEL «RENACIMIENTO» LITERARIO AL NACIONALISMO POLÍTICO? UNA COMPARACIÓN... 167

Cucó, A. (1999) [1971]. El valencianisme politic (1874-1939). Catarroja, Barcelona: Afers.

Dassance, L. (1922). L'Abbé Darrigol et le Prix Volney en 1829. Gure Herria, 10, 557-565.

Dávila Balsera, P. y Eizaguirre Sagardia, A. (1995). Las Fiestas Euskaras en el País Vasco (1879-1936). En P. Dávila Balsera (coord.). Lengua, escuela y cultura. El proceso de alfabetización en Euskal Herria (siglos XIX y XX) (pp. 257-311). Bilbao: Universidad del País Vasco.

Domingo, J. M. (2009). Renaixença: el mot i la idea. Anuari Verdaguer. Revista d'Estudis Literaris del Segle XIX, 17, 215-234.

Ensaig de ortografia catalana: estampat per manament del Consistori dels Jochs Florals en lo present any de gracia 1863 (1863). Barcelona: Imprenta y Llibreria de Salvador Manero.

Erize Etxegarai, X. (1997). Nafarroako euskararen historia soziolinguistikoa (1863-1936). Soziolinguistika historikoa eta hizkuntza gutxituen bizitza. Iruñea: Nafarroako Gobernua.

Espigado Tocino, G. (1990). El analfabetismo en España. Un estudio a través del censo de población de 1877. Trocadero. Revista de Historia Moderna y Contemporánea, 2, 173-192.

Ferrando, A. y Cortés, S. (eds.). (2007). Manuel Sanchis Guarner. Context, paraula, record. València: Universitat de València.

Figueres, J. M. (1986). El Diari Català (1879-1881): plataforma d'exposició del pensament catalanista. En Catalanisme: història, política i cultura (pp. 73-98). Barcelona: L’Avenç.

Fradera, J. M. (2003) [1992]. Cultura nacional en una sociedad dividida. Cataluña, 18281868. Madrid: Marcial Pons.

Freixes, A. (2012). Les Corts d'Amor en la gènesi del projecte floralesc. La redescoberta del certamen medieval. En J. M. Domingo (ed.). Joc literari i estratègies de representació. 150 anys dels Jocs Florals de Barcelona (pp. 81-124). Barcelona: Societat Catalana de Llengua i Literatura.

Fuster, J. (1977) [1956]. La poesia valenciana de Llorente als nostres días. En J. Fuster. Obres completes, vol. 5 (pp. 295-345). Barcelona: Ediciones 62.

- (1992) [1962]. Nosaltres, els valencians. Barcelona: Edicions 62.

Gellner, E. (1983). Naciones y nacionalismo. Madrid: Alianza Editorial.

Goyhenetche, J. (1993). Les origines sociales et historiques de l'association Eskualzaleen Biltzarra (1893-1913). Bulletin du Musée Basque, 135, 1-68.

Grau, R. y López, M. (1988). Antoni Puigblanch: una visió fatalista liberal del projecte nacional español. En A. Balcells (ed.). El pensament polític català (Del segle XVIII a mitjan segle $X X)$ (pp. 41-55). Barcelona: Edicions 62.

Hermida, C. (1992). Os precursores da normalización. Defensa e reivindicación da lingua galega no Rexurdimento (1840-1891). Vigo: Xerais.

Hina, H. (1986) [1978]. Castilla y Cataluña en el debate cultural (1714-1939). Historia de las relaciones ideológicas catalano-castellanas. Barcelona: Península.

Hobsbawm, E. J. (1991) [1990]. Naciones y nacionalismo desde 1780. Barcelona: Crítica.

Hroch, M. (1985) [1968]. Social Preconditions of National Revival in Europe. A Comparative Analysis of the Social Composition of Patriotic Groups among the Smaller European Nations. Cambridge: Cambridge University Press. 
- (2000) [1996]. In the National Interest. Demands and Goals of European National Movements of the Nineteenth Century: A Comparative Perspective. Prague: Charles University. (2015) [2005]. European Nations: Explaining Their Formation. London, New York: Verso.

Jacob, J. E. (1994). Hills of Conflict. Basque Nationalism in France. Reno, Las Vegas, London: University of Nevada Press.

Jorba, M. (1989). La polèmica de l'origen felibre o autòcton de la Renaixença. En A. M. Badia i Margarit y M. Camprubí (eds.). Actes del Vuitè Col.loqui Internacional de Llengua i Literatura Catalanes (pp. 343-363). Barcelona: Associació Internacional de Llengua i Literatura Catalanes, Abadia de Montserrat.

Juaristi, J. (1987). El linaje de Aitor. La invención de la tradición vasca. Madrid: Taurus.

- (1999). El "chimbo" expiatorio (La invención de la tradición bilbaina). Madrid: Espasa Calpe.

Kintana Goiriena, J. (2008). Intelektuala nazioa eraikitzen: R.M. Azkueren pentsaera eta obra. Bilbo: Euskaltzaindia.

Lamuela, X. y Murgades, J. (1984). Teoria de la llengua literària segons Fabra. Barcelona: Quaderns Crema.

Larronde, J. C. (1994). Le mouvement eskualerriste (1932-1937). Naissance du mouvement nationaliste basque en Iparralde. Bilbao: Fundación Sabino Arana.

Llobera, J. R. (1983). The Idea of Volksgeist in the Formation of Catalan Nationalist Ideology. Ethnic and Racial Studies, 6 (3), 332-350. Disponible en: https://doi.org/10.1080/0141 9870.1983 .9993417$.

Llorens i Vila, J. (1992). La Unió Catalanista i els origens del catalanisme politic. Dels orígens a la presidència del Dr. Martí i Julià (1891-1903). Barcelona: Abadia de Montserrat.

Llorente, T. (2013). Obra valenciana completa. Estudi i edició crítica a cura de Rafael Roca Ricart. València: Acadèmia Valenciana de la Llengua.

Llull, A. (1975). El mallorquinisme politic, 1840-1936 (Del regionalisme al nacionalisme). París: Edicions Catalanes de París.

Madariaga Orbea, J. (2008). Apologistas y detractores de la lengua vasca. San Sebastián: Fundación para el Estudio del Derecho Histórico y Autonómico de Vasconia.

Mainer, J. C. (2002). Notas sobre el regionalismo literario en la Restauración: el marco político e intelectual de un dilema. En J. C. Mainer y J. M. Enguita Utrilla (eds.). Entre dos siglos. Literatura y aragonesismo (pp. 7-26). Zaragoza: Institución Fernando el Católico.

Marfany, J. L. (1992). Mitologia de la Renaixença i mitologia nacionalista. L’Avenç, 164, 26-29.

(1995). La cultura del catalanisme. El nacionalisme català en els sues inicis. Barcelona: Empúries.

- (2001). La llengua maltractada. El castellà i el català a Catalunya del segle XVI al segle XIX. Barcelona: Empúries.

(2008) [2004]. Llengües sense estat i renaixences romàntiques. En J. L. Marfany. Llengua, nació i diglòssia (pp. 273-301). Barcelona: L’Avenç.

(2017). Nacionalisme espanyol i catalanitat (1789-1859). Cap una revisió de la Renaixença.

Barcelona: Edicions 62. 
Martel, Ph. (2004). Le Félibrige: un incertain nationalisme linguistique. Mots. Les Langages du Politique, 74, 43-57. Disponible en: https://doi.org/10.4000/mots.4273.

Miracle, J. (1960). La restauració dels Jocs Florals. Barcelona: Aymà.

Molas, J., Jorba, M. y Tayadella, A. (eds.). (1989). La Renaixença. Fonts per al seu estudi (18151877). Barcelona: Universitat de Barcelona, Universitat Autònoma de Barcelona.

Monteagudo, H. (1999). Historia social da lingua galega. Idioma, sociedade e cultura a través do tempo. Vigo: Galaxia.

Ninyoles, R. L. (1978) [1969]. Conflicte lingüistic valencià. Substitució lingüistica i ideologies diglòssiques. València: Eliseu Climent Editor.

Núnez Seixas, X. M. (2001). The Region as Essence of the Fatherland: Regionalist Variants of Spanish Nationalism (1840-1936). European History Quarterly, 31 (4), 483-518. Disponible en: https://doi.org/10.1177/026569140103100401.

- (2012). Historiographical Approaches to Sub-national Identities in Europe: A Reappraisal and Some Suggestions. En J. Augusteijn y E. Storm (eds.). Region and State in Nineteenth-Century Europe. Nation-Building, Regional Identities and Separatism (pp. 13-35). London, New York: Palgrave Macmillan.

- (2013). La(s) lengua(s) de la nación. En J. Moreno Luzón y X. M. Núñez Seixas (eds.). Ser españoles. Imaginarios nacionalistas en el siglo XX (pp. 246-286). Barcelona: RBA.

Pinyol i Torrents, R. (2012). Els dos Jocs Florals de 1888. En J. M. Domingo (ed.). Joc literari $i$ estratègies de representació. 150 anys dels Jocs Florals de Barcelona (pp. 327-352). Barcelona: Societat Catalana de Llengua i Literatura.

Pons i Pons, D. (1998). Ideologia i cultura a la Mallorca d'entre els dos segles (1886-1905). El grup regeneracionista de l'Almudaina. Palma: Lleonard Montaner Editor.

Prat de la Riba, E. (2000) [1898]. Compendi de la història de Catalunya. En E. Prat de la Riba. Obra completa, vol.1 (pp. 572-610). Barcelona: Institut d'Estudis Catalans, Proa.

- (2000) [1906]. La nacionalitat catalana. En E. Prat de la Riba. Obra completa, vol. 3 (pp. 117-170). Barcelona: Institut d'Estudis Catalans, Proa.

Puhle, H. J. (1982). Baskischer Nationalismus in spanischen Kontext. Geschichte und Gesellschaft, 8, 51-81.

Rafanell, A. (1991). Un nom per a la llengua. El concepte de llemosi en la història del català. Girona, Vic: Eumo, Estudi General de Girona, Estudis Universitaris de Vic.

- (2006). La il.lusió occitana. La llengua dels catalans entre Espanya i França. Barcelona: Quaderns Crema.

Riquer, B. de (1977). Lliga Regionalista: la burgesia catalana i el nacionalisme (1898-1904). Barcelona: Ediciones 62.

Risorgimento. (1949). En Enciclopedia Italiana di Scienze, Lettere ed Arti, vol. 29 (pp. 434-452). Roma: Istituto della Enciclopedia Italiana.

Roca Ricart, R. (2007). Teodor Llorente i la Renaixença valenciana. València: Institució Alfons el Magnànim.

- (2010a). El valencianisme de la Renaixença. Alzira: Bromera.

- (2010b). Teodor Llorente i la llengua dels valencians. Caplletra, 49, 43-63.

Rossich, A. (1994). Decadència i Renaixença: una visió programàtica de la literatura catalana. La literatura del XVI i del XVII vista des de la Renaixença. En Actes del Col.loqui Internacional sobre la Renaixença, vol. 2 (pp. 33-50). Barcelona: Curial. 
— (2006). Els certàmens: de la Gaia Ciència als Jocs Florals. En S. Martí (coord.). Actes del Tretzè Col.loqui Internacional de Llengua i Literatura Catalanes, vol. 1 (pp. 63-90). Barcelona: Associació Internacional de Llengua i Literatura Catalanes, Abadia de Montserrat.

Rubio Pobes, C. (2003). La identidad vasca en el siglo XIX. Discurso y agentes sociales. Madrid: Biblioteca Nueva.

Rubió y Ors, J. (1880). Breve reseńa del actual renacimiento de la lengua y literatura catalanas. Memorias de la Academia de Buenas Letras de Barcelona, III, 141-238.

Sánchez Prieto, J. M. (1993). El imaginario vasco. Representaciones de una conciencia histórica, nacional y politica en el escenario europeo (1833-1876). Barcelona: Ediciones Internacionales Universitarias.

Sanchis Guarner, M. (1974). Las dos vertientes, restauradora y progresista, de 'la Renaixença' valenciana. En Siete temas sobre historia contemporánea del País Valenciano. Ciclo de conferencias de la Facultad de Filosofía y Letras (pp. 135-154). Valencia: Universidad de Valencia.

Sarasola, I. (1982) [1971]. Historia social de la literatura vasca. Madrid: Akal.

Simbor Roig, V. (1980). Els orígens de la Renaixença valenciana. València: Universitat de València.

Solà, J. (1991). Episodis d'història de la llengua catalana. Barcelona: Empúries.

Soria Andreu, F. (2002). Tópicos y temas floralistas. En J. C. Mainer y J. M. Enguita Utrilla (eds.). Entre dos siglos. Literatura y aragonesismo (pp. 73-89). Zaragoza: Institución Fernando el Católico.

Thiesse, A. M. (2006). Centralismo estatal y nacionalismo regionalizado: Las paradojas del caso francés. Ayer, 64, 33-64.

Toledo Lezeta, A. M. (1998). Antoine d'Abbadie Hegoaldean (1879-1895). En Antoine d'Abbadie (1897-1997), Congrès International (pp. 535-546.). Bilbo, Donostia: Eusko Ikaskuntza, Euskaltzaindia.

Tomàs, M. (2012a). Els Jocs Florals de Barcelona i la literatura mallorquina del segle xix. En J. M. Domingo (ed.). Joc literari i estratègies de representació. 150 anys dels Jocs Florals de Barcelona (pp. 249-288). Barcelona: Societat Catalana de Llengua i Literatura.

- (2012b). Les relacions de Teodor Llorente amb Catalunya i Mallorca. En R. Roca (ed.). Teodor Llorente, cent anys després (pp. 31-71). Alacant: Universitat d'Alacant.

Torrealdai, J. M. (1997). Euskal kultura gaur. Liburuaren mundua. Ońati: Jakin.

Torrealday, J. M. (1977). Euskal idazleak, gaur. Historia social de la lengua y literatura vascas. Oñati: Jakin.

Tubino, F. M. (2003) [1880]. Historia del renacimiento literario contemporáneo de Cataluña, Baleares y Valencia. Pamplona: Urgoiti Editores.

Urkizu, P. (ed.). (1997). Anton Abbadiaren koplarien guduak. Bertso eta aire zenbaiten bilduma (1851-1897). Bilbo, Donostia: Eusko Ikaskuntza, Euskaltzaindia.

Verdaguer, J. (1974) [1888]. Pàtria. En J. Verdaguer (1974). Obres completes (pp. 407-458). Barcelona: Selecta.

Zabaltza, X. (2005). Mater Vasconia. Fueros, lenguas y discursos nacionales en los países vascos. San Sebastián: Hiria.

- (2006). Una historia de las lenguas y los nacionalismos. Barcelona: Gedisa. 